\title{
Diabetes Risk Obese Among Indonesian Adults with Metabolic Syndrome by 6-Years Prospective Cohort Study
}

\author{
Ekowati Rahajeng ${ }^{1, *}$, Eva Sulistiowati ${ }^{2}$, Nunik Kusumawardhani ${ }^{1}$ \\ ${ }^{1}$ Center for Public Health Research and Development, National Institute of Health Research and Development, Ministry \\ of Health, Jakarta, Indonesia \\ ${ }^{2}$ Center for Resources and Health Services Research and Development, Indonesia \\ * Corresponding Author. Email: ekowatir@gmail.com
}

\begin{abstract}
The prevalence of obesity is high in Indonesia. It was associated with the increasing prevalence of diabetes (DM). Metabolic syndrome (MS) is known could increase DM prevalence. It is important to understand if the DM incidence is higher among those who have MS among obese. Objective: To determine DM risk obese among Indonesian adults with MS. Methods: Since 2011, Indonesia has conducted a prospective cohort study of NCD risk factors in Bogor City. Incident of DM during a median follow-up of 6 years was assessed among 5192 adults include 752 adults with MS. Diagnosis of DM determined by clinical examination and fasting blood glucose levels, i.e. $\geq 126 \mathrm{mg} / \mathrm{dL}$ and/or results of blood glucose 2 hours after glucose load, i.e. $\geq 200 \mathrm{mg} / \mathrm{dL}$. Consistency of high BMI was used to define obesity $\left(\geq 30 \mathrm{~kg} / \mathrm{m}^{2}\right)$. MS was defined according to the criteria of the International Diabetes Federation (IDF). Results: The incidence rate of DM among adults with MS was 74 per 1,000 person-years. The incidence rate of DM among adult with MS and obese was 98 per 1,000 person-years. Meanwhile, among adult with MS but not obese was 25 per 1,000 person-years. In a multivariable model adjusted for age, sex, and family history of diabetes, a higher DM risk was observed among MS-obesecompared with MSnon obese (HR 3.64 [95\% CI 2.36-5.66]. Therefore, DM risk obese among Indonesian adults with MS is high. Interventional programs are important to MS treatment and obese prevention including promoting awareness of healthy lifestyle changes.
\end{abstract}

Keywords: metabolic syndrome, diabetes mellitus, obesity, incidence rate

\section{INTRODUCTION}

Various epidemiological studies indicate increased incidence and prevalence rates of type 2 Diabetes Mellitus (DM) worldwide. In Indonesia, the Basic Health Research in 2007, showed that the prevalence of DM in urban areas in Indonesia among adults was $5.7 \%$. In 2013, the prevalence has increased to $6.9 \%$, and in 2018 continued increased to 8.5 percent the prevalence of obesity is also increasing in the Indonesian adult population. The research shows that the prevalence of obesity in 2007 was $10.5 \%$, and has increased from $14.8 \%$ of the population in 2013 to $21.8 \%$ in 2018 . It was associated with the increasing prevalence of diabetes [1-3]. Metabolic syndrome (MS) is a complex constellation of risk factors that predispose to diabetes and coronary heart disease. Various components of the metabolic syndrome are abdominal obesity, impaired glucose regulation, dyslipidemias, and hypertension. Insulin resistance and obesity are characteristics of metabolic syndrome. The risk factors predispose to the development of diabetes and atherosclerosis [4-6]. The rising prevalence of obesity, metabolic syndrome, and diabetes mellitus has become a major problem.
Non-communicable diseases are estimated to account for $63 \%$ of all deaths in Indonesia. Cardiovascular disease contributed to $30 \%$ of the total number of deaths followed by cancers $(13 \%)$, and diabetes (3\%) [7-9]. The aim of the present study is to determine diabetes incidence rate and risk obese among Indonesian adults with metabolic syndrome by 6 years followup base on data of the prospective cohort study of NonCommunicable Diseases (NCD) risk factors in Bogor City West Java Indonesia. This information can serve as early warning tools for the Ministry of Health to develop a system and management program for obesity control and prevention of diabetes mellitus in Indonesia.

\section{METHOD}

The baseline data is Study Cohort of Non-Communicable Disases in Bogor City West Java, Indonesia. This study was approved by the Ethics Committee of the Health Research and Development Agency, Ministry of Health Indonesia. The study was conducted since 2011, which 
involved baseline cross-sectional survey and cohort followup every two years. The baseline sample is 5690 participants aged $\geq 18$ years old. Out of the 5129 participants, who did not have DM in 2011, and 752 cases have MS. The people who have DM and MS (consists of 408 persistent obese cases and 344 non-persistent obese cases during the cohort observation time) were able to participate in the follow up study on incidence of DM. The incident diabetes during a median follow-up of 6 years was assessed among 752 Indonesian adults with MS, and 211 were having DM cases but five cases were excluded due to having incomplete independent factors, which make in total 206. The flow diagram of this cohort sample is shown in Figure. 1. The baseline assessments included anthropometric measurements such as weight, height, and waist circumference (WC), assessment of blood pressure and biochemical parameters such as fasting plasma glucose, blood glucose 2 hours after glucose load, fasting total cholesterol, LDL-cholesterol, HDL cholesterol, and triglyceride. NCD risk factors were assessed using a structured interview schedule adapted from World Health Organization STEP instrument for NCD risk factor surveillance [10,11]. The interview schedule captured behavioral risk factors such as consumption of tobacco and alcohol, physical activity and diet as well as biological risk factors such as personal history of NCDs and family history of NCDs.

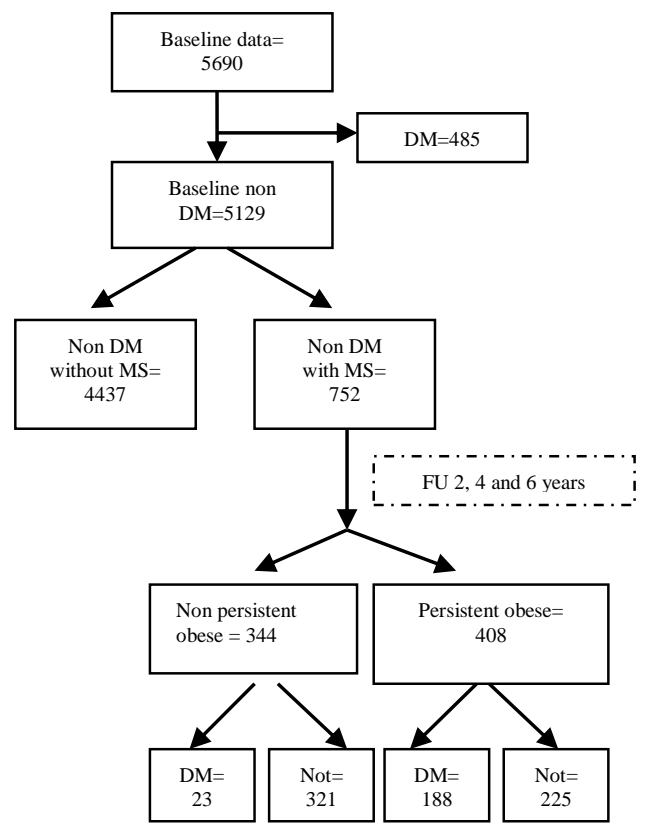

Figure 1. Flow chart on the study participants
Diagnosis of diabetes mellitus (DM) determined by clinical examination: Current use of hypoglycemic medication and/or fasting plasma glucose (FPG) levels, i.e. $\geq 126 \mathrm{mg} /$ $\mathrm{dL}$ and/or results of blood glucose 2 hours after glucose load, i.e. $\geq 200 \mathrm{mg} / \mathrm{dL}$, and/or Impaired Fasting Glucose (IFG) level is defined as FPG in the range $100-125 \mathrm{mg} / \mathrm{dL}$ without being on hypoglycemic medication. One of the following defines Hypercholesterolemia: Current use of lipid lowering medication and/or F TC>200 mg/dL Body Mass Index (BMI) is a person's weight in kilograms divided by the square of height in meters. Consistency of high BMI ( $\left.\geq 30 \mathrm{~kg} / \mathrm{m}^{2}\right)$ was used to define continuous or persistent obesity. Central obesity was defined as per Asian cut off for WC (male's $\geq 90 \mathrm{~cm}$ and female's $\geq 80 \mathrm{~cm}$ ) [6].

MS was defined according to the criteria of the International Diabetes Federation (IDF) definition, for a person to be defined as having MS they must have: Central obesity plus any two of the following four factors: raised Triglyceride level: > $150 \mathrm{mg} / \mathrm{dL}$, reduced HDL cholesterol: < $40 \mathrm{mg} / \mathrm{dL}$ ( in males and $<50 \mathrm{mg} / \mathrm{dL}$ in females, raised blood pressure: systolic BP $\geq 130$ or diastolic $\mathrm{BP} \geq 85 \mathrm{~mm} \mathrm{Hg}$, and raised fasting plasma glucose $(\mathrm{FPG}) \geq 100 \mathrm{mg} / \mathrm{dL}$. Each $\mathrm{MS}$ group was further divided according to the number MS present at enrollment. MS1 (Central Obesity plus two factors), MS2 (Central Obesity plus three factors), and MS3 (Central Obesity plus four factors) [3,9].

Data analyses were done using IBM SPSS Statistics for windows v21.0. The descriptive characteristics of participants were described in mean and ANOVA test. Person time denominator for assessing incidence rate estimated based on the assumption that DM (event) occurred at the median of the interval (6 years). The hazard ratios (HRs) and 95\% CIs of obese at enrollment on diabetes risk using Cox proportional hazards analysis adjusted for, sex, age, family history of diabetes, Next, the cohort was divided into three groups based on obese and the number of cumulative metabolic abnormalities. The additional metabolic parameters only at baseline, since these variables might be part of the causal chain.

Cox proportional hazards models were used to estimate the incidence rate and 95\% CI for developing diabetes across the four categories. MS participants with non-persistent served as the reference group. Multivariable models were adjusted for sex, age, and family history of diabetes, with additional adjustment for the metabolic risk factors (FPG, triglyceride level, HDL-cholesterol, and systolic blood pressure) where appropriate. Additional analysis was conducted using repeated assessments of obese during the follow-up period as time-dependent variables in a Cox regression model. 


\section{RESULTS AND DISCUSSION}

This study showed distribution of metabolic syndrome (MS) cases with obesity and central obesity that most of the respondents with central obesity in this study $68.75 \%$ of them was having two MS, while $27.79 \%$ of respondents was diagnosed with three MS, and $3.46 \%$ of respondents was diagnosed with four MS (see Figure 2). While looking at the mean value of age and MS levels (Table 1), those who had both central obesity and four MS were older age, higher systolic and diastolic, higher total blood cholesterol, higher HDL, higher triglyceride, and higher fasting blood glucose levels, with significant differences (ANOVA test showed $\mathrm{p}=0001$ ). Meanwhile mean value of BMI, waist circumference and LDL in those three group were no significantly different (ANOVA test $p>0,05$ ).

Table 1. Characteristics respondents with obesities central and metabolic syndrome symptoms

\begin{tabular}{|c|c|c|c|c|c|}
\hline Caracteristics & $\begin{array}{c}\text { Central } \\
\text { obesity +2 } \\
\text { MS symptoms }\end{array}$ & $\begin{array}{c}\text { Central obesity } \\
+3 \text { MS } \\
\text { symptoms }\end{array}$ & $\begin{array}{c}\text { Central obesity } \\
+4 \mathrm{MS} \\
\text { symptoms }\end{array}$ & $\mathrm{F}$ & $\mathrm{p}$ \\
\hline Age & $45,8 \pm 9,5$ & $47,5 \pm 8,9$ & $52,3 \pm 6,6$ & 7,638 & 0,001 \\
\hline BMI & $29,1 \pm 4,0$ & $29,5 \pm 4,0$ & $29,0 \pm 3,0$ & 0,821 & 0,440 \\
\hline WC & $91,0 \pm 7,9$ & $91,8 \pm 8,2$ & $92,8 \pm 8,5$ & 1,104 & 0,332 \\
\hline FPG & $85,9 \pm 10,4$ & $88,0 \pm 10,2$ & $107,1 \pm 5,7$ & 54,226 & 0,001 \\
\hline HDL & $44,8 \pm 8,6$ & $40,8 \pm 5,9$ & $38,4 \pm 4,9$ & 25,438 & 0,001 \\
\hline LDL & $134,6 \pm 34,0$ & $136,7 \pm 34,4$ & $143,5 \pm 34,8$ & 1,012 & 0,364 \\
\hline Cholesterol & $209,6 \pm 42,0$ & $220,2 \pm 38,1$ & $229,6 \pm 31,2$ & 7,224 & 0,001 \\
\hline Triglycerides & $149,7 \pm 86,9$ & $212,3 \pm 77,7$ & $239,4 \pm 101,8$ & 49,301 & 0,001 \\
\hline Sytolic & $141,5 \pm 24,4$ & $149,2 \pm 22,9$ & $162,9 \pm 25,2$ & 15,493 & 0,001 \\
\hline Diastolic & $88,6 \pm 11,8$ & $92,1 \pm 10,9$ & $97,1 \pm 12,6$ & 11,774 & 0,001 \\
\hline
\end{tabular}

Table 2 show a total of 206 new cases of diabetes were diagnosed during 2766 person-years of follow-up among adult with MS, the incidence rate DM was 74 per 1,000 person-years. Figure 3 shows that DM cumulative hazard function was linear with the number of MS factors. It can be seen that the DM cases were increasing in year 2, 4 and 6 cohort years. It shows that the more the number of MS the more DM case was found.

Table 2. Cumulative incidence of Diabetes Mellitus among Population with MS

\begin{tabular}{|l|c|c|l|l|}
\hline Interval & Censore & $\begin{array}{c}\text { Number } \\
\text { of } \\
\text { Termina } \\
\text { Start }\end{array}$ & $\begin{array}{l}\text { perso } \\
\text { n }\end{array}$ & $\begin{array}{l}\text { Hazard } \\
\text { Rate }\end{array}$ \\
Time & d Events & years & DM \\
\hline 2 years & 87 & 79 & 253 & \\
4 years & 47 & 43 & 317 & \\
6 years & 296 & 84 & 2196 & \\
\hline \multicolumn{2}{|l|}{ Cumulative Incidence } & 206 & 2766 & 0,074 \\
\hline
\end{tabular}

This study found 183 new cases of DM among those who had obese and MS during the cohort years of 1861 personyears, while the incidence rate of DM was 98 per 1,000 person-years, At the other hand, it was found about 23 new cases of DM among those who had MS without obese condition during the observation of 905 person years, with the DM incidence rate of 25 per 1,000 person years (Table $3)$.

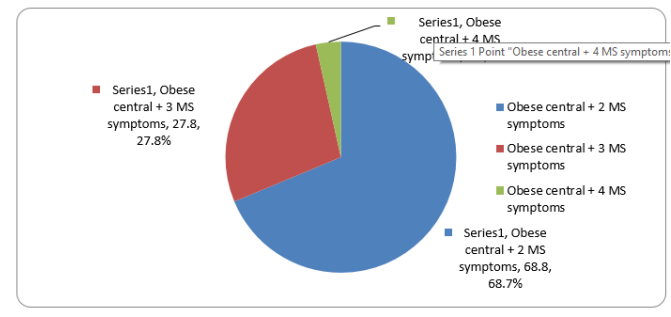

Figure 2. Percentage of respondents with obesities central + MS symptoms

Table 3. Cumulative incidence of DM in MS with and without persistent obese condition

\begin{tabular}{|c|c|c|c|c|}
\hline Interval Start Time & Censored & $\begin{array}{c}\text { Number of } \\
\text { Terminal } \\
\text { Events }\end{array}$ & $\begin{array}{l}\text { person } \\
\text { years }\end{array}$ & $\begin{array}{l}\text { Hazard } \\
\text { Rate }\end{array}$ \\
\hline Persistent Obese & & & & \\
\hline 2 years & 7 & 70 & 84 & \\
\hline 4 years & 10 & 38 & 154 & \\
\hline 6 years & 208 & 75 & 1623 & \\
\hline Cumulative Inciden & & 183 & 1861 & 0,098 \\
\hline $\begin{array}{l}\text { Non Persistent } \\
\text { Obese }\end{array}$ & & & & \\
\hline 2 years & 80 & 9 & 169 & \\
\hline 4 years & 37 & 5 & 163 & \\
\hline 6 years & 88 & 9 & 573 & \\
\hline Cumulative Inciden & & 23 & 905 & 0,025 \\
\hline
\end{tabular}

The analysis showed that Hazard Function of DM cumulatively linear with the number of DM cases and several MS factors which was described from results from the three groups: MS1 ; Central Obesity + two factors MS (Figure 3), MS2 : Central Obesity + three factors MS (Figure 4), and MS3 :Central Obesity + four factors MS (Figure 5). It is indicated that DM cumulative incidence most likely higher among those who had both MS and obesity compare to those who had MS without obese condition. 
Table 4. Multivariate Analysis of Diabetes Risk Among

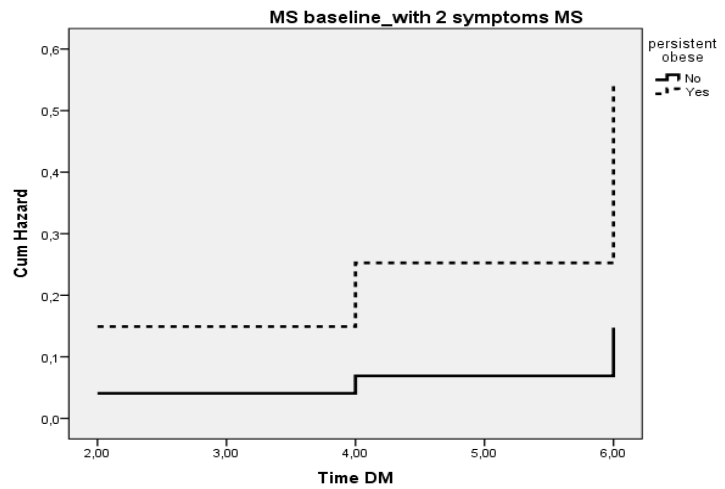

Figure 3. Hazard ratio DM in MS1 with persistent obese

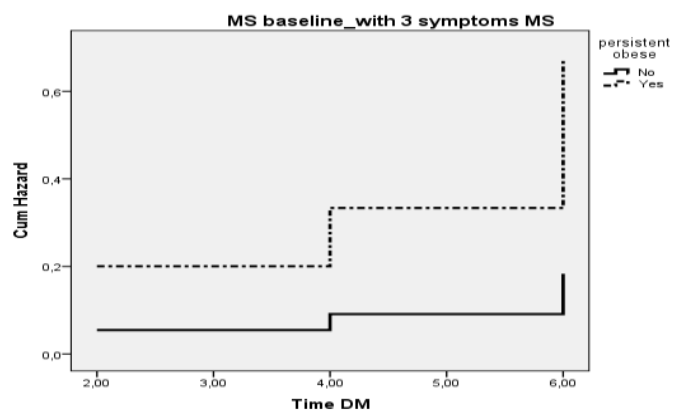

Figure 4. Hazard ratio DM in MS2 with persistent obese

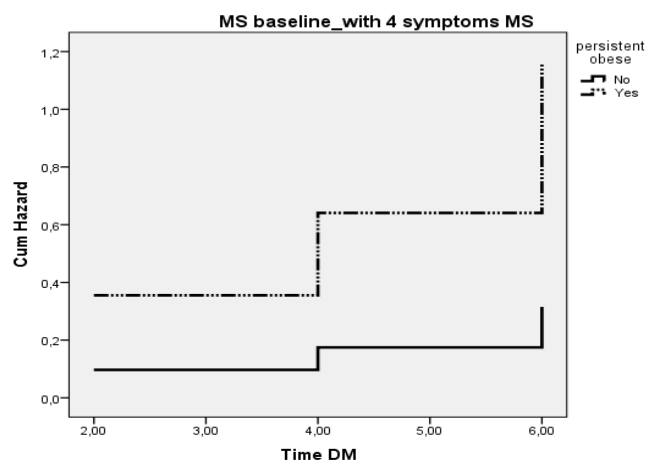

Figure 5. Hazard ratio DM in MS3 with persistent obese

In a multivariable model adjusted for age, sex, and family history of diabetes (Table 4), a higher diabetes risk was observed among MS-obese (HR 3.66 [95\% CI 2.36-5.66]; $\mathrm{P}<0.001)$ compared with MS-non obese, and also age has contributed to increasing DM incidence, particularly at the age of 45 years and older.
Obese With Metabolic Syndrome

\begin{tabular}{|l|c|c|c|}
\hline Variable & Exp $(\boldsymbol{\beta})$ & $\mathbf{9 5 \%}$ CI & p \\
\hline Age groups & & & 0,001 \\
\hline $25-34$ & - & - & \\
\hline $35-44$ & 1.791 & $0.978-3.279$ & \\
\hline $45-54$ & 2.661 & $1.504-4.705$ & \\
\hline$\geq 55$ & 3.445 & $1.922-6.175$ & \\
\hline Gender & & & 0,750 \\
\hline Male & - & - & \\
\hline Female & 0,944 & $0.665-1.342$ & \\
\hline Family history DM & & & 0,081 \\
\hline No & - & - & \\
\hline Yes & 1.352 & $0.963-1.898$ & \\
\hline Persistent obese & & & 0,001 \\
\hline No & - & - & \\
\hline Yes & 3.664 & $2.369-5.668$ & \\
\hline
\end{tabular}

The NCDs cohort study in Bogor City west Java in 2018 reported that the diabetes mellitus incidence rate in adult population was 29 per 1000 person years (95\% CI 27.0 31.7) [12]. This six years cohort study described that DM incidence rate among those with MS (IDF criteria) was 74 per 1,000 persons-years, which was higher compare to those without MS [13]. Previous analysis from the same cohort, found that 161 respondents $(4.8 \%)$ had developed DM, which consisted of 42 men (4.2\%) and 119 women (5.2\%) the two-years of follow-up[14,15]. With median duration of follow up was 7.5 years, the incidence rate of DM among the people aged 20-74 years in Yazd Iran, was 21,4 per 1000 person years[16].

Study in middle-aged Mexican adults of the metabolic syndrome cohort found the incidence rate (IR) in the whole population was 21.9 cases per 1000 persons/year (95\% CI 21.37-22.47) with a higher rate observed in men (IR 22.4 (95\% CI 21.5-23.4) . Other study showed Study age- and sex-standardized diabetes incidence rates based on MS criteria by WHO criteria had a much higher incidence of diabetes than those who did not (IRR 3.58, 95\% CI 2.56 5.00), meanwhile increased incidence occurred in those who met NCEP criteria compared with those who did not was lower (2.09, 95\% 1.49-2.92) [17-20].

The Bogor study report identified that the predictors of DM among adult (Age adjusted) were hypertrigliceridemia ( $\geq 150 \mathrm{mg} / \mathrm{dl}$ ), obesity ( $\geq 25 \mathrm{~kg} / \mathrm{m} 2$ ), hypertension, and family history of DM. Predictor of DM among those who had MS in this cohort were obesity and age of 45 years and older. Previous analysis by Sirait AM and Sulistiowati E identified the MS components that strongly associated with DM incidence was fasting blood glucose level with RR 6.71 fold (95\% CI; 4.76 - 9:47) [14]. An increase in 
fasting blood sugar levels and glucose load MS criteria is a risk factor for DM. Sulistiowati E and Sihombing M analysis earlier, the 3344 non-cohort respondents who were evaluated in the 2 nd year showed that respondents with IFG within 2 years were in condition of $46.8 \%$ of their blood sugar levels returned to normal; $16.9 \%$ remained in the IFG condition; $10.4 \%$ became IGT and $11.7 \%$ became DM [16].

There are limited data relating MS with obese factors to incidence of DM. A longitudinal study of DM that has been conducted among residents of the Gila River Indian Community in central Arizona found that the body size and lipids factors significantly predicted diabetes (IRR 1.52 and 1.37, respectively, $P<0.01$ for both). The risk of DM among obese with MS cases was higher (HR 3.66 [95\% CI 2.36-5.66]; $\mathrm{P}<0.001)$ [16].

Analysis of previous cohort studies of 3324 non-DM respondents aimed at looking at the prevalence of MS showed that MS based on the NCEP ATP III and IDF criteria were $17.1 \%$ and $15.6 \%$, respectively. At 2-year follow-up, type 2 diabetes occurred in $13.0 \%$ of respondents who experienced MS NCEP-ATP III criteria and $12.6 \%$ in IDF criteria. The risk for developing type $2 \mathrm{DM}$ in subjects with MS NCEP-ATP III and IDF criteria was 4.7 (95\% CI: 3.4-6.5) and 4.1 (95\% CI: 3.0- 5.7) [16].

As it has been described earlier, in general, this cohort study showed that one of the ten obese cases were also having MS condition, in which ignorance of this condition will lead to diabetes mellitus after one year period. It is clearly proven that one or more MS condition can be a strong determinant of type 2 Diabetes Mellitus. Behavior change toward health life style and secondary prevention with more focus on those who are in age of 45 years are the key intervention to prevent diabetes mellitus.

The mechanism causing the occurrence of the metabolic syndrome is based on insulin resistance and central obesity (visceral fat). Visceral fat is metabolically more active than peripheral fat. The accumulation of adipocytes will increase the free fatty acids (FFA) resulting from lipolysis, which will reduce the sensitivity to insulin. This insulin resistance and hyperinsulinemia in turn will cause metabolic changes, leading to hypertension, dyslipidemia, increased inflammatory responses and coagulation, by means of complex mechanisms such as endothelial dysfunction and oxidative stress $[5,17,25]$.

This study has described that the number of metabolic syndrome components associated with the risk of DM. According to a sub-study on 3,323 members of the Framingham Heart Study Offspring Study, the risk for DM had increased with the number of metabolic syndrome components when the NECP criteria were applied. The adjusted RR for participants with three abnormalities or four more abnormalities was 4.56 (95\% CI 2.48-8.78) and 10.88 (95\% CI 5.77-20.50), respectively, in the British Regional Heart study. Metabolic syndrome can be a specific composite pattern of risk factors that bring the individual in greater risk of having diabetes. Several conditions of metabolic syndrome include abdominal obesity, impaired glucose regulation, dyslipidemias and hypertension [18-26].

Metabolic syndrome and pre-diabetes are closely related to the incidence of DM and cardiovascular disease. A systematic review by Grundy showed that the RR of CVD in pre-diabetes (IFG = Impare Fasting Glucose) $1.2(95 \%$ CI: 1.12-1.28). BC increases the risk of CVD 2-fold due to the high proportion of patients with $\mathrm{BC}$ who have a component of pre-diabetes [25]. Meanwhile, Church et al's study shows that CVD deaths are higher in men with MS (HR 1.8 (95\% CI 1.5-2.0), diabetes (2.9 (95\% CI 2.1-4.0) and both (MS and DM) HR 3.4 (95\% CI 0.8-1.7) [26].

\section{CONCLUSION}

Diabetes risk obese among Indonesian adults with MS is high. Interventional programs are important to MS treatment and obese prevention including promote awareness healthy lifestyle changes in the community. Changes in the life style, reduction of obesity and food habits are fundamental in reducing the risk factors. Some patients may, however, require pharmacological intervention for the control of hyperglycemia, obesity, hypertension and dyslipidemias.

\section{REFERENCES}

[1] Tao Z, Shi A, Zhao J. Epidemiological perspectives of diabetes. Cell Biochem Biophys 2015;73(1):181e5.

[2] National Institute of Health Research and Development. Population Health Basic Health Research - RISKESDAS 2007. Indonesia Jakarta: Ministry of Health Republic of Indonesia Jakarta; 2008

[3] National Institute of Health Research and Development. Population Health Basic Health Research - RISKESDAS 2013. Indonesia Jakarta: Ministry of Health Republic of Indonesia Jakarta; 2014

[4] National Institute of Health Research and Development. Population Health Basic Health Research - RISKESDAS 2018. Indonesia Jakarta: Ministry of Health Republic of Indonesia Jakarta; 2018

[5] Alberti, K.G., Eckel, R.H., Grundy, S.M. et al, Harmonizing the metabolic syndrome: a joint interim statement of the international diabetes federation task force on epidemiology and prevention; national heart, lung, and blood Institute; American heart association; world heart federation; international atherosclerosis society; and international association for the study of obesity. Circulation. 2009;120:16401645

[6] Chan J, Malik V, Jia W, Kadowaki T, Yajnik C, Yoon K, Hu F. Diabetes in Asia: epidemiology, risk factors, and 
pathophysiology. JAMA. 2009;9(20):2129_ 2140. doi: 10.1001/jama.2009.726. [PubMed] [CrossRef] [Google Scholar]

[7] World Health Organization. Global Health Observatory. http://www.who.int/gho], Accessed 01.03.2012.

[8] Website of the World Health Organization: Indonesia - NCD profile. 2010. [http://www.who.int/nmh/countries/idn_en.pdf ], Accessed 14.12.2018

[9] Website of the International Diabetes Federation. IDF Diabetes Atlas Update. 2012. [ http://www.idf.org/diabetesatlas/previousedit ions], Accessed 32.11.2018.

[10] World Health Organization. Noncommunicable Diseases and Their Risk Factors: STEPwise Approach to Surveillance (STEPS). Geneva: World Health Organization; 2003. Available from: http://www.who.int/ncds/surveillance/ste ps/en/. [Last accessed on 2018

[11] WHO STEPS Surveillance Manual. The WHO STEPwise approach to Noncommunicable Disease Risk Factor Surveillance. World Health Organization. Available from: http://www.who.int/ncds/surveillance/ste ps/STEPS Manual.pdf. [Last accessed on 2018 Sep 06].

[12] Certer for Research and Development of Public Health Effort. National Institute of Health Research and Development. Report of Study Cohort of Non Communicable Disases 2018. Indonesia Jakarta: Ministry of Health Republic of Indonesia Jakarta; 2018

[13] Sirait AM, Sulistiowati E. Metabolic Syndrome in Adult in Bogor City, 2011-2012. Media Litbangkes $2014 \quad ; \quad 24$ (2): 81-8. DOI: $10.22435 / \mathrm{mpk} . v 24 \mathrm{i} 2.3565 .81-88$

[14] Sulistiowati E dan Sihombing $M$. Perkembangan Diabetes Melitus Tipe 2 dari Prediabetes di Bogor, Jawa Barat. Jurnal Penelitian dan Pengembangan Pelayanan Kesehatan. 2018; 2 (1): 59-69.

[15] Sulistiowati E dan Sihombing M. DM tipe 2 pada responden sindroma metabolik berdasarkan kriteria IDF dan ATP III modifikasi di lima kelurahan Kota Bogor. Univ Med. 2016; 35 (1): 46-56.

[16] Gilad Twig et al. Diabetes Risk Among Overweight and Obese Metabolically Healthy
Young Adults. Diabetes Care 2014;37:2989_ 2995.

[17] Hadaegh F, Ghasemi A, Padyab M, et al The metabolic syndrome and incident diabetes: assessment of alternative definitions of the metabolic syndrome in an Iranian urban population. Diabetes Res Clin Pract 2008; 80: 328-334 [PubMed] [Google Scholar]

[18] Shin Jeong- Ah, Lee Jin- Hee, Lim SunYoung, et all. Metabolic syndrome as a predictor of type 2 diabetes, and its clinical interpretations and usefulness. J Diabetes Investig. 2013 Jul 8; 4(4): 334-343. Published online 2013 May. doi: 10.1111/jdi.12075

[19] Read, S.H., Kerssens, J.J., McAllister, D.A. et al, Trends in type 2 diabetes incidence and mortality in Scotland between 2004 and 2013. Diabetologia. 2016;59:2106-2113

[20] Geiss, L.S., Wang, J., Cheng, Y.J. et al, Prevalence and incidence trends for diagnosed diabetes among adults aged 20 to 79 years, United States, 1980-2012. J. Am. Med. Assoc. 2014;312:1218-1226

[21] Lin, S., Naseri, T., Linhart, C. et al, Diabetes incidence and projections from prevalence surveys in Samoa over 1978-2013. Int. J. Publ. Health. 2017;62:687-694

[22] Morrell, S., Lin, S., Tukana, I. et al, Diabetes incidence and projections from prevalence surveys in Fiji. Popul. Health Metrics. 2016; $14: 45$

[23] Lin, S., Naseri, T., Linhart, C. et al, Trends in diabetes and obesity in Samoa over 35 years, 1978-2013. Diabet. Med. 2017;34:654-661

[24] Yi, S.W., Ohrr, H., Shin, S.A. et al, Sex-agespecific association of body mass index with all-cause mortality among 12.8 million Korean adults: a prospective cohort study. Int. J. Epidemiol. 2015;44:1696-1705

[25] Grundy Scott M. Pre-Diabetes, Metabolic Syndrome, and Cardiovascular Risk. Journal of the American College of Cardiology. 2012; 59 (7): 635-643.

[26] Church Timoty S, et al. Metabolic Syndrome and Diabetes, Alone and in Combination, as Predictors of Cardiovascular Disease Mortality Among Men. Diabetes Care. 2009;32 (7): 1289-1294. 